\title{
Production of Scientific Articles on COVID-19 in Student Research Committees of Medical Universities
}

\author{
Pourya Pezeshgi $^{*}$ iD , Mehdi Akbari Soufiani ${ }^{1}$ iD Arian Tarahomi $^{2}$ iD
}

1. Student Research Committee, Maragheh University of Medical Sciences, Maragheh, Iran

2. Faculty of Medicine, Semmelweis University, Budapest, Hungary

\begin{tabular}{c} 
Received: 2021/08/25; Accepted: 2021/11/07; Published Online: 2021/12/08 \\
\hline Corresponding Information: $\begin{array}{l}\text { Pourya Pezeshgi, Student Research Committee, Maragheh University of Medical Sciences, Maragheh, Iran, Email: } \\
\text { Pezeshgipourya@yahoo.com }\end{array}$ \\
\hline c) Copyright @ 2021, This is an original open-access article distributed under the terms of the Creative Commons Attribution-noncommercial 4.0 International License which \\
\hline permits copy and redistribution of the material just in noncommercial usages with proper citation.
\end{tabular}

Use your device to scan and read the article online

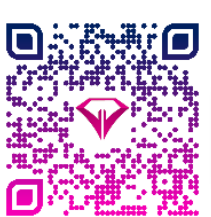

Pezeshgi P, Akbari Soufiani M, Tarahomi A. Production of Scientific Articles on COVID-19 in Student Research Committees of Medical Universities. Iran J Med Microbiol. 2021; 15 (6) :708-710

Download citation:

Send citation to:
Mendele
2 Zotero

B] RefWorks

\section{Dear Editor}

Coronavirus infection is nowadays a major public health issue that has affected societies and economics worldwide. Therefore, it is necessary to conduct various research to find how the disease affects human health. In this regard, the Student Research Committees (SRC), subdivision of research vice-chancellor of Iranian Universities of Medical Sciences, have effectively provided a suitable platform for medical students to learn how to conduct scientific research (1). Given that medical students in the future will be the university professors and health policymakers, the cooperation of the university and professors with SRCs can provide a good opportunity for students to gain their research potential both theoretically and in practical application for analyzing the research data, problem solving and having experience to cope with the challenges and problems of health and wellness. Considering that COVID-19 is currently one of the most fundamental health issues in the world and also in our country, we attempted to evaluate the research output of SRCs in the field of COVID-19.

Using various affiliations of the Student Research Committee (Student Research Center, Student Research Committee, Student Scientific Research Committee, and Students' Scientific Research Center) and search for the keywords "COVID-19" OR "2019-nCoV
Infection" OR "2019- nCoV Infections" OR "Coronavirus Disease-19" OR "2019 Novel Coronavirus" OR "2019-nCoV Disease" OR "2019-nCoV Diseases" OR "Coronavirus Disease 2019" OR "SARS Coronavirus 2 Infection" OR "SARS-CoV-2 Infection" OR "SARS-CoV2 Infections". In the Scopus database, published articles on COVID-19 were reviewed in collaboration with the SRC. This search was done on August 16, 2021. The number of scientific papers and citations of SRCs of medical universities in the field of Covid-19 is shown in Figure 1 based on the classification of the Vice Chancellor for Research and Technology.

SRCs have published 337 articles on COVID-19 in the Scopus database, including 180 articles in 2021 and 157 articles in 2020. The total number of citations to SRC articles so far is 2421. According to Figure 1, $16.3 \%$ of the articles and $27.2 \%$ of the citations are related to the SRC of Shahid Beheshti University of Medical Sciences, which shows the continuous activity of this committee in research related to COVID-19. The three faculty authors who had the most cooperation with the SRC in this field are related to Shahid Beheshti University of Medical Sciences. This cooperation of professors with students would be an essential factor affecting students' motivation for research activities. According to the scientometrics 
system of SRCS of medical universities of the country, the research activity of the SRC of Shahid Beheshti University of Medical Sciences has always been growing, which shows the increased motivation and spirit of cooperation among students of this university in the field of research. In this context, the programs and progress of Shahid Beheshti University of Medical Sciences SRC can be considered a model for other universities to focus on the potential and capability of young student researchers to deal with these concerning health challenges and issues. It is suggested that the heads and other members of the Central Council of Shahid Beheshti University of Medical Sciences SRC transfer their experiences and strategies in motivating and increasing the spirit of cooperation among the other members of SRCs, especially type 2 and 3 medical universities. Given that students are the future of this country, conducting research in the field of COVID-19 among students can lead to the development of new ideas in young people and have the power to deal with the fundamental health issues of the country.

\section{Type 1 Universities of Medical Sciences}

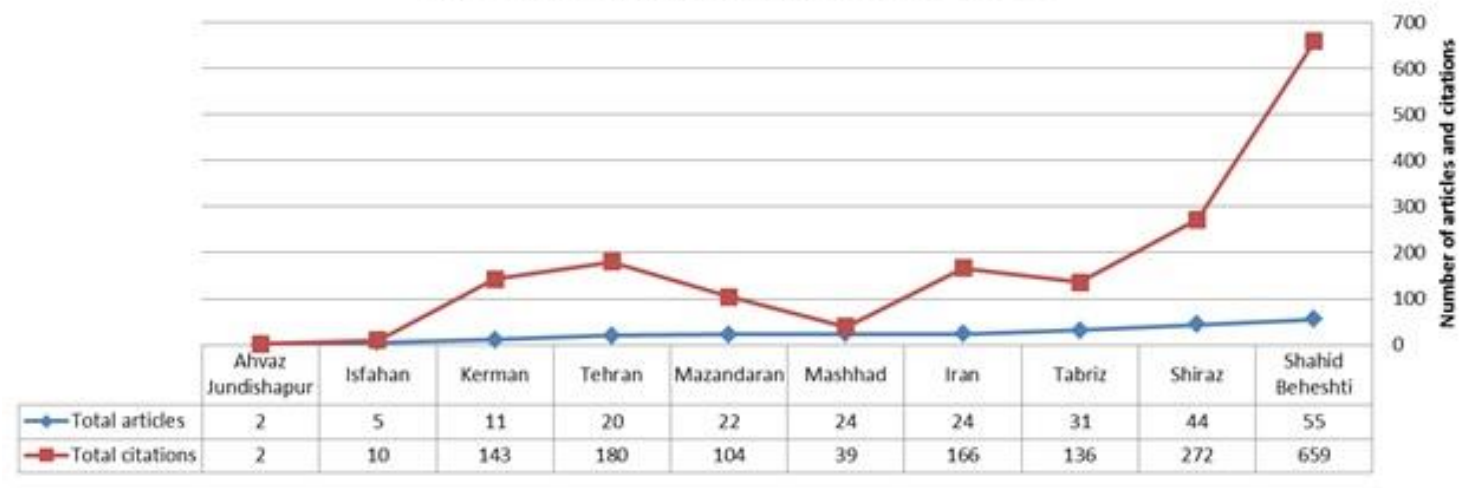

Type 2 Universities of Medical Sciences

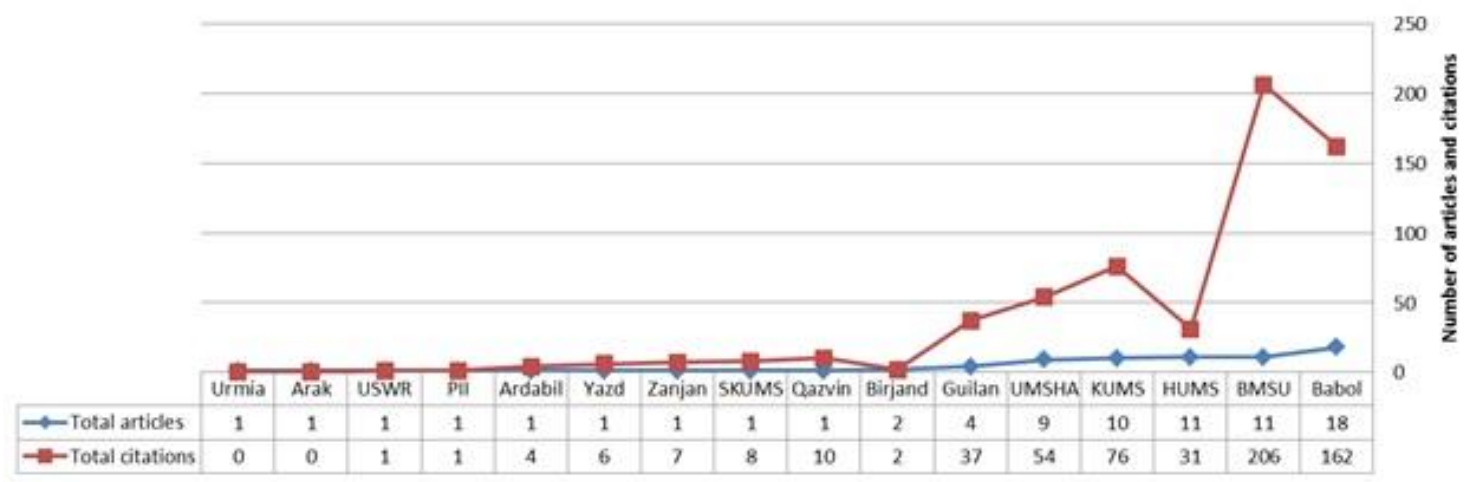

Type 3 Universities of Medical Sciences

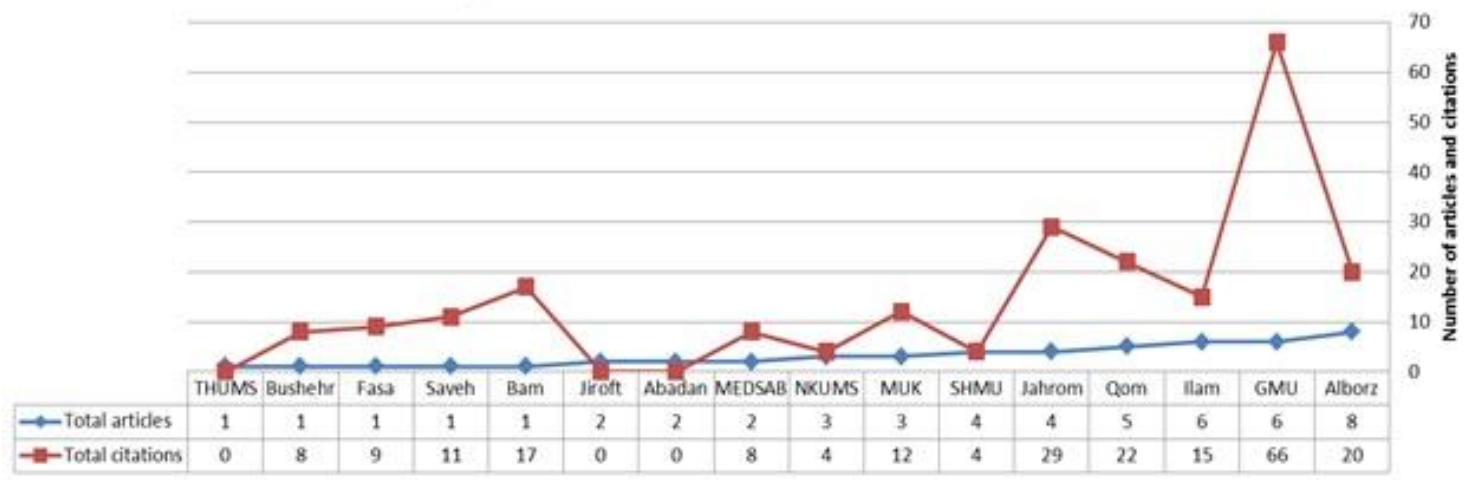

Figure 1. Number of scientific articles and citations of SRCs of medical universities in the field of COVID-19 (separation based on classification of Vice Chancellor for Research and Technology) 
BMSU, Baqiyatallah University of Medical Sciences; HUMS, Hormozgan University of Medical Sciences; KUMS, Kermanshah University of Medical Sciences; UMSHA, Hamadan University of Medical Sciences; Shahrekord University of Medical Sciences; PII, Pasteur Institute of Iran; University of social welfare and rehabilitation; GMU, Gonabad University of Medical Sciences; SHMU, Shahroud University of Medical Sciences; MUK, Kurdistan University of Medical Sciences; NKUMS, North Khorasan University of Medical Sciences; MEDSAB, Sabzevar University of Medical Sciences; THUMS, Torbat Heydariyeh University of Medical Sciences.

\section{References}

1. Shakiba B, Irani S, Salmasian H. A jumpstart for student researchers in Iran. The Lancet. 2007;369(9568):1167-8. [DOI:10.1016/S01406736(07)60560-1]

\section{Acknowledgment}

We would like to thank Dr.Janahmadi for proofreading and sharing her experiences with us.

\section{Authors' Contributions}

All authors have equally contributed to this paper.

\section{Funding}

None.

\section{Conflict of Interest}

P.P. and M.A.S. were members of Student Research Committee in Maragheh University of Medical Sciences. A.T. has no conflict of interest. 